\title{
Analysis of price change on the perceptions and use of DMPA among clients using reproductive health services in Uttar Pradesh, India
}

Leila Caleb-Varkey

John Townsend

Population Council

Sneh Vishwanath

Sudha Tiwari

Follow this and additional works at: https://knowledgecommons.popcouncil.org/departments_sbsr-rh

Part of the Demography, Population, and Ecology Commons, Health Services Research Commons, and the International Public Health Commons

How does access to this work benefit you? Let us know!

\section{Recommended Citation}

Caleb-Varkey, Leila, John Townsend, Sneh Vishwanath, and Sudha Tiwari. 1998. "Analysis of price change on the perceptions and use of DMPA among clients using reproductive health services in Uttar Pradesh, India," Asia and Near East OR/TA Project Final Report. Dhaka: Population Council. 


\section{Analysis of Price Change on the Perceptions and Use of DMPA among Clients using Reproductive Health Services in Uttar Pradesh, India}

\section{FINAL REPORT}

Leila Caleb-Varkey

John W. Townsend

Population Council
Sneh Vishwanath

Sudha Tiwari

Parivar Seva Sanstha

Sub-contract No. CI96.12A

Asia \& Near East Operations Research and

Technical Assistance Project

27 March 1998 


\section{Table of Contents}

Acknowledgment

Summary

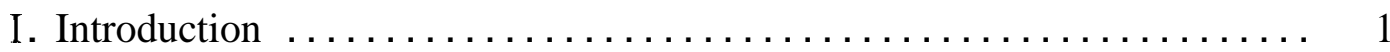

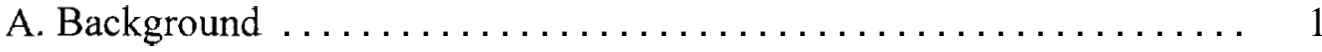

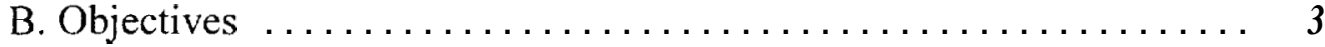

II. Research Methods $\ldots \ldots \ldots \ldots \ldots \ldots \ldots \ldots \ldots \ldots \ldots \ldots \ldots \ldots \ldots$

A. Design . . . . . . . . . . .

B. Parivar Seva Sanstha and Collaborators $\ldots \ldots \ldots \ldots \ldots \ldots \ldots \ldots \ldots$

C. Site Selection . . . . . . . . .

D. Subjects and Informed Consent $\ldots \ldots \ldots \ldots \ldots \ldots \ldots \ldots \ldots \ldots, 8$

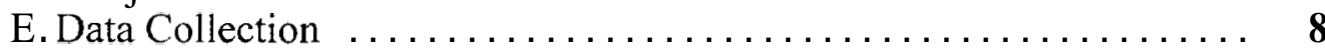

F. Research Management $\ldots \ldots \ldots \ldots \ldots \ldots \ldots \ldots \ldots \ldots \ldots .9$

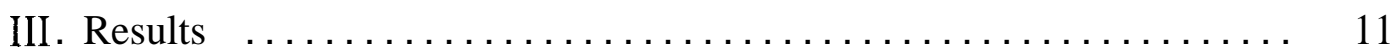

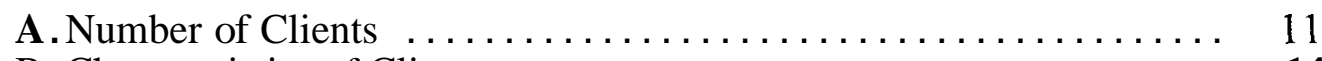

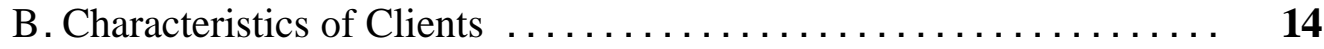

C. Client Perceptions of DMPA Experience $\ldots \ldots \ldots \ldots \ldots \ldots \ldots \ldots . \ldots \ldots 21$

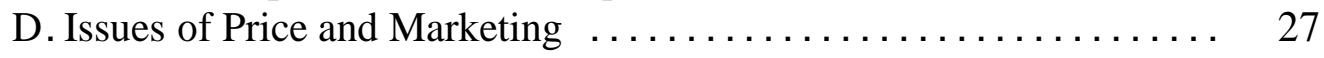

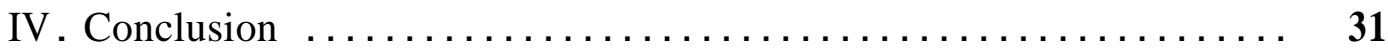

References 


\section{Acknowledgment}

This study, conducted by Parivar Seva Sanstha (PSS) was supported by the Population Council's Asia and Near East Operations Research (ANE OR/TA) Project, under Contract No. CI96.12A. Financing was provided by the United States Agency for International Development, Office of Population. Health and Nutrition.

The collaborating institutions wish to acknowledge, and thank the following individuals for their contribution to this study

- Parivar Seva Sanstha (PSS) under the leadership of Mrs. Sudha Tiwari.

- The Principal Investigators: Dr. Sneh Vishu anath. Dr. Meena Singh

Finance Officer: Mr. Harbans Singh

Research Coordinators: Ms. Mandita Wahi, Ms. Urvashi Sharma,

Ms. Ananya Jaiswal. and Ms. Megha Sharma

- The Parivar Seva Sanstha staff at all three clinics:

Ms. Meera Mankad, Dr. Annapurna Sodhi and Dr. S.D. Misra in Agra

Ms. Sudha Misra, Dr. Seema Goyal. I)r. Meena Singh and Dr. Vidhu Srivastava in Lucknow

Ms. Sushmita Ghoshal and Dr. Renu Singh in Varanasi

- Dr. Leila Caleb Varkey and Dr. John W. Townsend for technical assistance in the development of the research, data analysis and report preparation. Special thanks are also due to Dr. Saumya RamaRao for conducting the cost analysis, and Dr. Jayanti Tuladhar and Dr. M.E. Khan for their technical support.

- Mr. Saumitro Ghosh of ADMAR for the conduct of the qualitative study

- Mr. S.S. Modkar of SOMARC and Mr. John Pile of AVSC for sharing DMPA related information. 


\section{Summary}

Depo-medroxy Progesterone Acetate (DMPA) is a progesterone-only injectable contraceptive, that is provided in three-monthly doses. It has been approved by the Government of India for provision in the commercial sector in India, where it is marketed under the brand name Depo-Provera and can be procured on a doctor's prescription. During 1996 it was available at rates that range between Rs. 140 to Rs. 180 per injection. At this price, however it is often beyond the reach of many women wanting a safe and effective contraceptive. Because of the progesterone content, it is indicated for use by lactating women. Its side effects are related to initial disturbances in the menstrual cycle, from irregular spotting or bleeding to complete amenorrhoea. Fertility usually returns within nine months of last injection.

In January 1996, DMPA was provided to women in three cities of Uttar Pradesh, specifically Agra, Lucknow, and Varanasi through Parivar Seva Sanstha's (PSS) clinics at Rs 150. PSS is the Indian affiliate of Marie Stopes International. In July 1996, as part of the operations research the price of DMPA was reduced in Agra to Rs. 50, in Varanasi to Rs. 0 and Lucknow to Rs. 100. with an initial clinical examination charge of Rs. 40 at all clinics Information was collected on these services and clients for a total of eighteen months, to understand how price influenced the demand, perceptions and use of DMPA among urban women in Uttar Pradesh at different prices. The study seeks to better understand client perspectives on the product and its price, and in this context it should not be viewed as a traditional clinical trial. Since awareness about injectable contraceptives was very low in these cities, initial publicity about the method was undertaken. This was done at the three cities through fortnightly advertisements in the Sunday edition of local editions of Hindi newspapers as well as in three editions of two women's interest magazines, wall paintings and billboards.

The injectable was provided by PSS under conditions where the quality of counseling about side effects was standardized and could be monitored. Information and educational material on the range of contraceptive methods offered at the clinics were provided to all prospective clients, and additional material and a client appointment card was given to each woman accepting DMPA Clients were encouraged to return to the clinics for further counseling if needed and side effect follow-up was provided at no additional charge. No further effort was made for follow-up if a client did not return to the clinic.

In all a total of 662 women accepted at least one dose of DMPA during April 1996 to September 1997. Sixty-four percent of the women had used a modern method of contraception earlier. The most commonly mentioned methods were condoms (64 percent), IUD (33 percent) and pills ( 24 percent). After the price change, the increase in use of DMPA was highest at Varanasi. and lowest at Lucknow. However the effect of the price change was not sustained over time, as the clinics registered a decline in new acceptors after the initial rise 
The greatest barrier to first time use was lack of knowledge of anyone who had actually used DMPA, and a fear of possible side effects, especially amenorrhea or absence of menstrual periods. Fifty-four percent of the first injections were given to women following an MTP. In general DMPA represented 5-8 percent of the total family planning visits at the PSS clinics.

Continuation of the product was low, with only 44 percent of users returning for a second dose, and 29 percent seeking a third dose. Only 19 percent of acceptors used DMPA through one year (4 doses). Continuation rates among clients improved significantly over the study period. More than half of the clients ( 55 percent) who received their first injection during the second half of the study returned for the second dose and 39 percent for the third dose. The median duration of use was about 6 months. Among all users, many lapsed because of side effects, primarily amenorrhea, followed by irregular menstrual periods. Price was not mentioned as a reason for not taking the next injection. No pregnancies were reported among users of DMPA during the study period. A follow-up of 114 women who had stopped using the method, indicates that the most commonly mentioned contraceptive methods used following discontinuing of DMPA were condoms (26 percent), orals (18 percent), IUD ( 7 percent) and tubectomy ( 7 percent). About 40 percent stated that they were not using any method.

From a management perspective, the most significant factor for PSS in sustaining the sale of this product was the wholesale price, i.e. Rs. 95 when the study began and currently about Rs. 120. A cost analysis identified wholesale price as the most critical issue for PSS. Per 100 clients, Lucknow would be the only clinic to have a positive income from DMPA services at the current price to clients (Rs. 100), if advertising costs were not included. All other clinics provided DMPA at a loss, given the high wholesale cost of the commodity. All other associated service costs, with the exception of advertising, were relatively modest. Estimates suggest that Rs. 35 would be an affordable wholesale cost for PSS, compatible with the current pricing strategy in both Lucknow and Agra. If supplies could be obtained at below Rs. 35, then obviously net income would increase, other things being equal.

In conclusion, DMPA appears to be an acceptable, safe method of contraception when offered in a context of good client counseling and follow-up. By providing DMPA, PSS offered a broader contraceptive choice to their clients. More effective public information about the method and its availability would greatly improve its access. Ensuring the availability of the product at an affordable wholesale price in India would both meet the needs of potential clients as well as facilitate the financial sustainability of the service by PSS. 


\section{Introduction}

\section{A. Background}

Depo-medroxy Progesterone Acetate (DMPA) is a progesterone-only injectable, that is provided in three-monthly doses. About I 2 million couples throughout the world now use DMPA and other injectable contraceptives, approximately 3 percent of contraceptive users. DMPA is approved for use in 106 countries. Table 1 provides contraceptive prevalence data by method for selected countries the region (WHO, 1994). Examining the proportion of modern method use represented by DMPA, injectables account for about 14 percent of users in Bangladesh, 29 percent in Indonesia, 8 percent in Nepal, 11 percent in Pakistan, 7 percent in Sri Lanka and 17 percent in Thailand. Data on contraceptive method use in India from the National Family Health Survey (IIPS, 1993) and from sample surveys in selected districts of Uttar Pradesh (BSUP, 1996) show clearly that injectable contraceptive use is negligible, less than one percent of family planning users. To date, injectable contraceptives are still not provided within the Indian family welfare programme. In contrast, injectables have been part of the Bangladesh family welfare programme since 1976.

Table 1 Spacing Method Use by Country

\begin{tabular}{|l||c||c||c||c||}
\hline \hline Country & $\%$ DMPA & $\%$ Orals & $\%$ IUD & $\begin{array}{l}\% \text { Modern } \\
\text { Method Use }\end{array}$ \\
\hline \hline India & 0 & I & 2 & 41 \\
Bangladesh & 5 & 17 & 2 & 36 \\
Indonesia & 15 & 15 & 13 & 52 \\
Nepal & 2 & 1 & $<1$ & 24 \\
Pakistan & 1 & I & 2 & 13 \\
Sri Lanka & 3 & 4 & 2 & 41 \\
Thailand & 12 & 19 & 7 & 69 \\
\hline
\end{tabular}

Source: WHO, 1994

Under the brand name Depo-Provera, the three month injectable (DMPA) produced by Pharmacia \& Upjohn has been approved since 1993 by the Drug Controller of India. It is licensed for distribution in the commercial sector on prescription by private physicians. A two-monthly injectable. NET-EN produced by Shering AG, 
is also marketed through private physicians. The products and the duration of their effect are indeed different, but the medium of administration is the same. Injections of DMPA can be administered by paramedical or medical staff, and are given in the muscle of the arm or buttock.

Injectable contraceptives combine high levels of effectiveness with reliable reversibility (Population Reports, 1987). Moreover, as a progestin-only product, DMPA does not have an adverse effect on lactation, an important feature in India where lactation commonly extends to more than one year postpartum. Most trials report less than one percent method failure, making injectables comparable with most clinical methods. In terms of reversibility. a study conducted by the Indian Institute for Medical Research (ICMR) study found that 69 former injectable users (NET-EN) conceived on average of 11 months after their last injection (ICMR, 1990).

The ICMR study also reported that disruption of regular menstrual bleeding and amenorrhoea are the most common side effects of the progesterone-only injectables (NET-EN) and the main reason women stop using them (ICMR, 1990). Counselling on these side effects is an important element of service delivery and a major determinant of satisfaction and continuation. In Ecuador, DMPA users in private clinics actually experienced slightly fewer side effects, and fewer accidental pregnancies than pill users (Foreit, 1995). Certain groups do have different experiences with the product. For example. in Turkey a study reported that the continuation rate for postabortion clients for the first year of DMPA use (47 percent) was lower than that for interval and postpartum users (Pile, 1998). Philippines data suggests that spousal support is also important for continuation (Costello, 1995).

The precise annual cost for methods provided through the public sector in India is difficult to determine. However, IJNFI'A estimates the comparable cost per couple year of protection (CYP) for methods provided by the public sector in India to be US $\$ 0.50$ for sterilization, US\$0.80 for the IUI), US\$2.30 for pills and US $\$ 4.00$ for condom (UNFPA, 1993). The private sector also supplies all these methods at market and subsidized prices through private physicians as well as commercial and social marketing programs. Physicians seem quite interested in injectables. For example. a recent Indian Medical Association (IMA) training evaluation suggested that IMA affiliated physicians were interested in learning about DMPA. and their knowledge about the method increased signific antly during training (CORT, 1995). However, DMPA and Net-EN are methods that are not available in the public sector and are only available at commercial prices through chemists and private physicians.

Product price is one of the major factors affecting access, adoption and continuation. A review of 15 experimental progranis suggests that charging a tnodest fee for contraceptive services and products (rather than providing them free) does not have a negative effect on demand. Price reductions c onsistently, however, led to increases 
in demand. Furthermore, efforts designed to recover the full costs often deter lowincome and moderate income clients from seeking the service (Lewis, 1986). Similarly high prices dampen sales and tend to shift users to other sources or less expensive methods (Lewis, 1992). For example, in 1990 Bangladesh increased prices in their social marketing program by about 60 percent in the hope of recovering more costs, and as a result sales of orals dropped by 12 percent and condoms by 29 percent (Ciszewski and Harvey, 1995).

Distribution of DMPA in India is currently being conducted through the commercial sector to private physicians. The prices mentioned by women who bought DMPA in Lucknow in April 1995 was Rs. 140 to Rs. 180. DMPA can be obtained wholesale through large pharmacies with clinic discounts for about Rs. 110 to 124 . Pharmacia \& Upjohn report that the slow pace of marketing of the product has been deliberate, given the interest in quality and the upscale market segment which has been targeted. But sales have been modest. For example, a Retail Store Audit conducted monthly throughout the country shows that in Uttar Pradesh no more than 600 vials were sold per quarter since April 1996 (ORG, 1997).

A post-marketing surveillance study sponsored by Pharmacia \& Upjohn is underway nationally with 10 reporting sites to identify potential clinical problems associated with longer term DMPA use, as well as look at issues of acceptability in the private sector. Parivar Seva Sanstha (PSS), the Marie Stopes Affiliate in India, participated in this post-marketing surveillance study. The clinical experience of PSS with DMPA users suggests that the dynamics of DMPA use in India in terms of client concerns, effectiveness and side effects is similar to that reported in the international literature (Population Reports, 1987). 'The interest of PSS in expanding the contraceptive options available for women forms that backdrop for this study on clients' choices and product price.

\section{B. Objectives}

The following were the principal objectives of the operations research:

- To broaden the choice of affordable contraceptive methods available to PSS clients.

- To examine the differences in demand, client profile and satisfaction with DMPA at three prices to clients. This would lead to policy recommendations on the use of the method in different cost settings within PSS.

- Contribute additional data to the policy debate on the role of injectables in India. 
The study hypothesized that reductions in the price of DMPA increases contraceptive choice. The study aimed to assess which price most closely met the clients' perceptions of an affordable, good quality. contraceptive service, and at the same time ensured the financial sustainability of the service from the provider's perspective.

\section{Research Methods}

\section{A. Design}

A mix of qualitative and quantitative research methods were used to assess client demand and satisfaction with the product in three Parivar Seva Sanstha (PSS) clinics in Uttar Pradesh at three price levels, all currently below the prevailing PSS price of Rs. 150. Three PSS clinics in Varanasi, Agra and Lucknow were assigned a different price to be charged to clients for DMPA. The prices of DMPA in the three settings were as follows: Rs.0 in Varanasi, Rs. 50 in Agra and Rs. 100 in Lucknow. With the high wholesale cost of DMPA supplies (Rs. 95). the service was heavily subsidised at the first price, modestly subsidized at the second price, and available at about the wholesale price in the private sector in India at the third price. At the time of initial acceptance, the clients were charged an additional gynaecological examination charge of Rs. 40 at all clinics. Communication materials to support client counselling were developed and distributed at the clinics. All follow-up services related to side effects were free.

The research design is illustrated below:

$\begin{array}{llllll}\text { Varanasi Clinic (Rs. 0) } & \text { O1 } & \text { X } & 02 & \text { X+A } & 03 \\ \text { Agra Clinic (Rs. 50) } & 01 & \text { X1 } & 02 & \text { X1+A } & 03 \\ \text { Lucknow Clinic (Rs. 100) } & 01 & \text { X2 } & 02 & \text { X2+A } & 03\end{array}$

$\mathrm{O} 1=$ Observations on client characteristics and demand prior to the price change.

$02=$ Observations on client characteristics and demand following price change.

$03=$ Continuation and follow-up of users, and estimation of the effect of advertising.

$\mathrm{X}=$ DMPA provided at Rs. 0 plus examination charge of Rs 40 and no charge for subsequent injections.

$\mathbf{x} \mathbf{l}=$ Product provided at Rs. 50 for first and subsequent injections with Rs. 40 examination charge.

$\mathrm{x} 2=$ Project provided for Rs. 100 for first and subsequent injections plus Rs 40 for examination charge at first injection.

$\mathrm{A}=$ Advertising 
The study seeks to better understand client perspectives on the product and its price, and in this context it should not be viewed as a traditional clinical trial. To protect the confidentiality of client identity, no attempt was made to follow-up on all clients who accepted DMPA.

\section{Advertising the Availability of DMPA}

As DMPA is a relatively little known product in India, the design also included an embedded test of the impact of low level advertising on the demand for the service. In all three cities, advertising of the availability of DMPA was conducted by PSS through local print media, specifically Hindi newspapers and magazines, and the use of billboards and wall paintings in neighbourhoods served by PSS. The content and layout of the adverstisments were based on suggestions from focus group discussions, and proofs were pretested with potential clients prior to publication.

The advertising consisted of 24 advertisements, each about 14 square cm., which were published fortnightly in the Sunday edition of two leading Hindi newspapers in each city. The newspapers included: Amar Ujala, Dainik Jaggran, Rashtriya Sahara and Aaj. The articles and ads in women's magazines were placed in Sarita and Griha Shobha. The ads provided limited information about the availability of the DMPA service and specified the price charged at the nearest PSS clinic. The advertisments were published from October 1997 to March 1998.

Simultaneously PSS contracted for one bill board and several wall paintings in strategic locations to inform potential clients about the new product. Agra also contracted about 10 kiosks on a busy street to advertise the service. Copies of orientation materials on DMPA and its characteristics were also sent to a local mailing list of private physicians for their information and referral.

\section{B. Parivar Seva Sanstha (PSS) and Collaborators}

PSS is a non-profit society registered in 1978, under the Societies Registration Act of 1860. It is affiliated with Marie Stopes International, and manages 30 reproductive health clinics throughout India. PSS has reproductive health service projects in the New Delhi, and the states of Uttar Pradesh, Haryana, Rajasthan, Madya Pradesh, Himachal Pradesh, West Bengal, Tamil Nadu and Karnataka among others. Its donors include DFID, SOMARC, SIFPSA, European Union, the Population Foundation of India and USAID. It not only operates reproductive health clinics, but also is involved in reproductive health training and education, social marketing, community based distribution of contraceptives, family life education and orientation for adolescents. 
It has 30 clinics and 3 outreach projects, and is an affiliate of Marie Stopes International, London and its clinics are sometimes called "Marie Stopes Clinics". PSS had introduced DMPA as a contraceptive choice in a few selected clinics in August 1994 at Rs. 150, along with a gynaecological check-up charge of Rs 40-50. From January 1996 it was offered in all 30 clinics. In one of PSS's outreach projects in Mewat, Haryana, DMPA was also made available through home visits at Rs. 20 per dose with high levels of acceptance.

As implementing agency, PSS was responsible for identification of the sites, specific pricing strategies, staff arrangements and overall management for the project. PSS also identified a source for supply of DMPA, and was responsible for the purshase of supplies. MaxPharma, the Indian company contracted by Pharmacia \& Upjohn to supply DMPA to the national market, stopped its supply in January 1997. Thereafter. Pharmacia \& Upjohn assumed direct responsibility for supply and distribution of DMPA. During the short period when commercial market supplies were not available, PSS clinics did not face any shortage of DMPA as in-house stocks were sufficient.

The Population Council provided technical assistance to PSS on the overall injectable strategy, in the conduct of the research, including data analysis, and in the preparation of reports. Direct observations of counseling and care were made, and interviews with providers and clients were conducted during routine visits by Council staff to the service sites. Data collection from DMPA client intake forms was the responsibility of the PSS physicians at the clinics, with the supervision and support of the project director. Media and message components of advertising were done by PSS in collaboration with IMAGINE. an advertising and communications firm in New Delhi. The qualitative follow-up research to analyse the perceptions of nonusers, lapsed users and current users was conducted by the New Delhi based social marketing group, ADMAR Private Services Limited.

\section{Site Selection}

The present study took place in the three largest PSS clinics in Uttar Pradesh (e.g. Agra, Varanasi, Lucknow). All clinics provide a wide range of family planning and gynaecological services, and DMPA is simply mentioned during counselling as one of the options available. At least one wall chart in each clinic identifies the methods available. Public sector contraceptives, e.g. condoms and orals, are provided free of charge, while social marketing products are charged at the following rates: four Bliss or Sawan condoms for Rs. 2, and one cycle of Ecroz for Rs. 6. There is no charge for a copper IUD T200A, although a gynaecological exam is charged at Rs. 40. Both female and male sterilization services are provided free, and the government sanctioned user fee is paid to clients to cover. their expenses, Rs. 145. Medical Termination of Pregnancy (MTP) services are offered as well, and are charged on a 
sliding rate depending on the number of weeks ofpregnancy, e.g. 6-8 weeks, Rs. 375 or Rs. 475 for $10-12$ weeks.

The Lucknow clinic is located in the state capital, with an urban female population of reproductive age of approximately 363,000. The PSS clinic is in a rented facility, with the clinic on the first floor. It has been in the same location, a side street off a major thoroughfare, for about four years. This clinic is staffed by two women physicians, all who provide client screening, counselling and injectables. Prior to the study (since August 1994), the clinic had been providing DMPA to a total of about 190 clients. About half of the DMPA clients received the first injection post-MTP. Monthly provision of injections ranges from 10 to 22 clients, with about half being first injections. A small number of clients have continued for one year, but two injections is the most common duration of use in each clinic. The providers suggest that the principal reasons for drop out are the high cost of the product, amenorrhoea and spotting. During January 1996, PSS served 475 clients. About one-third of the clients seek an MTP. and about half are interested in other women's health services.

The Agra clinic is located in the large industrial and tourist city, with an urban population of about 231,000 women of reproductive age. The clinic is also in a rented house; it has limited space but operates very efficiently. It has provided DMPA since December, 1995, and reported 11 J)MPA users prior the study. Most clients are poor and many come from rural areas as far as 40 kilometres from Agra for clinical services. The medical staff is composed of one-full time and two parttime women physicians. all with $\mathrm{Ob} / \mathrm{Gyn}$ degrees or diploma training. Like in the Lucknow clinic, they are largely responsible for screening, counselling and providing injections. Counselling is done in a small partitioned counselling room. During January 1996, the clinic served 935 clients of which 312 attended the clinic for MTP.

The Varanasi clinic is located near the train station on a busy road in this traditionally religious Hindu city, with an urban population of about 276,000 women of reproductive age. The clinic has been in the same location for the last eight years, but Marie Stopes has offered clinical services in Varanasi for over 12 years. The clinic is staff by two full-time women physicians. two nurses, one clinic attendant, one operating theatre attendant, and one manager/counsellor. DMPA has been provided in the clinic since December 1994, and served a total of 22 users of injections prior to the study. Most have used only one dose, and none has used more than two doses. As in the other clinics, price and amenorrhoea are the principal stumbling blocks for greater acceptance. During December 1905, the PSS clinic served about 375 clients, of which 204 attended PSS for an MTP.

All three clinics are located in accessible inner city areas, are well marked, and have attractive facilities relative to the local market They offer basic laboratory facilities 
for identifying blood type, and conducting haemoglobin and urine tests. They provide pap smears on request, but the slides are sent to a referral clinical laboratory. PSS also cooperates with the public sector in major campaigns, such as the recently completed Pulse Polio immunization drive and adolescent girls' Iron Supplementation campaign.

All clinics maintain records of demographic and medical profiles of clients, including data on age, profession, income, education, menstrual history, obstetric and contraceptive history, lactation, the result of medical examination, and the schedule for follow-up visits to the clinic for each client. It is PSS policy to limit follow-up of clients in the community to protect their confidentiality. In addition, the clinics keep a simple DMPA users register, with information on name, age, parity, address, and dates of injections, as well as remarks. A pregnancy test was available to DMPA users, who were concerned about amenorrhoea. Clinical examinations and menstrual history were more commonly used to rule out pregnancy at the first visit.

\section{Subjects and Informed Consent}

All clients at PSS are offered the range of contraceptive methods available at PSS, including IUDs, orals, condoms, sterilization and DMPA. All clients are provided counseling and have access to IEC materials. Selection of the particular method is voluntary and based on informed consent. All women for whom DMPA was not contraindicated and who chose the method were eligible for the study. All clients were counselled about side effects and, if accepting DMPA and willing to be followed-up at home, were asked to sign a consent form. All clients were assured of the confidentiality of the information they provided. The identity of users was only available to the clinicians and the research team. Client records were maintained in a locked cabinet. Clients were assured that they could discontinue use of DMPA or drop out of the study for any reasons, without consequences.

\section{E. Data Collection}

Table 2 provides a list of the source of information used for individual data variables. Data collection took place over a period of $\mathbf{1 8}$ months, and also included:

- The number of DMPA vials and syringes in stock were routinely monitored. This information was maintained by the clinic manager and reviewed at the PSS central office and at the time of visits by PSS and Council staff. Standards for safety and disposal procedures for DMPA materials were reviewed in July 1996, and checked periodically during clinic site visits.

- Information on counselling and quality of care was collected by direct observation at all three clinics by Population Council staff and interviews with 
providers. Quarterly meetings were held to assist in problem solving and sharing analysis with clinic staff.

An analysis of the cost to PSS of providing DMPA in each of the three sites was conducted by the Population Council in January 1997.

\begin{tabular}{|c|c|c|c|}
\hline $\begin{array}{l}\text { Data Collection } \\
\text { Methodology } \\
\end{array}$ & $\begin{array}{l}\text { Number } \\
\text { Interviewed }\end{array}$ & Information Collected & |Variables \\
\hline $\begin{array}{l}\text { ORG Retail Shelf } \\
\text { Audits. }\end{array}$ & -- & $\begin{array}{l}\text { Total value and volume of DMPA } \\
\text { sold through commercial channels. }\end{array}$ & $\begin{array}{l}\text { Commercial sale of } \\
\text { DMPA in UP. }\end{array}$ \\
\hline $\begin{array}{l}\text { Structured Client } \\
\text { Intake fonn for all } \\
\text { women accepting } \\
\text { DMPA. }\end{array}$ & $\begin{array}{l}\text { Total: } 662 \\
\text { 165-Lucknow } \\
\text { 199-Agra } \\
\text { 298-Varanasi }\end{array}$ & $\begin{array}{l}\text { Demographic and economic profile } \\
\text { of ustrs. Reasons for selecting } \\
\text { DMPA. Prior contraceptive use and } \\
\text { reasons tor accepting contraception. }\end{array}$ & $\begin{array}{l}\text { Demographic, } \\
\text { obstetric and } \\
\text { contraceptive use } \\
\text { data on clients. }\end{array}$ \\
\hline $\begin{array}{l}\text { Group Discussions } \\
\text { (GDs) with women } \\
\text { not using DMPA in } 3 \\
\text { cities. }\end{array}$ & $\begin{array}{l}3 \text { GDs per } \\
\text { city. Each } \\
\text { GD } 8-10 \\
\text { women }\end{array}$ & $\begin{array}{l}\text { Perceptions of awareness and use of } \\
\text { FP methods, and specifically } \\
\text { perceptions of DMPA. }\end{array}$ & $\begin{array}{l}\text { What is the general } \\
\text { awareness of DMPA } \\
\text { among potential users. }\end{array}$ \\
\hline $\begin{array}{l}\text { In-depth interviews } \\
\text { with women who } \\
\text { discontinued DMPA } \\
\text { use. }\end{array}$ & $\begin{array}{l}\text { Total: } 114 \\
\text { 38-Lucknow } \\
\text { 40-Agra } \\
\text { 36-Varanasi }\end{array}$ & $\begin{array}{l}\text { Perceptions of DMPA, level of } \\
\text { satisfaction and reasons for } \\
\text { discontinuing method. Sensitivity } \\
\text { to price change. }\end{array}$ & 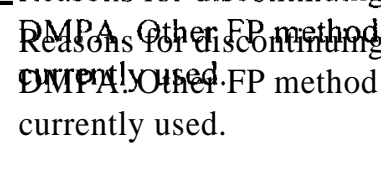 \\
\hline $\begin{array}{l}\text { In-depth interviews } \\
\text { with women who are } \\
\text { currently using } \\
\text { DMPA. }\end{array}$ & $\begin{array}{l}\text { Total: } 176 \\
\text { 55-Lucknow } \\
\text { 60-Agra } \\
\text { 61-Varanasi }\end{array}$ & $\begin{array}{l}\text { Perceptions and use of DMPA, side- } \\
\text { effects and their management. } \\
\text { Purchase intent at different prices. }\end{array}$ & $\begin{array}{l}\text { Reasons for continuing } \\
\text { DMPA. Other issues } \\
\text { related to price. }\end{array}$ \\
\hline $\begin{array}{l}\text { Clieıt cards on FP use } \\
\text { from all PSS clinics. }\end{array}$ & $\begin{array}{l}30 \text { PSS } \\
\text { clinics }\end{array}$ & $\begin{array}{l}\text { Relative provision of different } \\
\text { family planning methods. }\end{array}$ & $\begin{array}{l}\text { Method mix in all PSS } \\
\text { clinics. }\end{array}$ \\
\hline
\end{tabular}

\section{F. Research Management}

Table 3 highlights the major activities and their placement in the time line from April 1996 to September 1997. The major events included the training of staff and the development of IEC materials on CMPA for clients and providers, focus group discussion with clients, the management of price changes, development of an advertising strategy and campaign, the cost analysis and the follow-up study.

To assist in the coordination of these activities at the clinic level, quarterly meetings were held with PSS New Delhi staff, clinic managers and doctors. Meetings were 
organized by Dr. Sneh Vishwanath, the principal investigator from PSS, New Delhi with Drs. Leila Caleb-Varkey and John Townsend of the Population Council. Review meetings were held in April 1996 in New Delhi, October 1996 in Agra, February 1997 in Lucknow and July 1997 in Varanasi.

Table 3 Study Time Line by Quarter Apr 1996 to Sep 1997

\begin{tabular}{|l|l|l|l|l|l|l|l|l||}
\hline \hline ACTIVITY/ QUARTER & 1 & 2 & 3 & 4 & 5 & 6 \\
\hline \hline Training of staff and development of materials & $\mathrm{X}$ & & & & & \\
\hline Focus group discussions & $\mathrm{X}$ & $\mathrm{X}$ & & & $\mathrm{X}$ & \\
\hline Price change & & $\mathrm{X}$ & $\mathrm{X}$ & $\mathrm{X}$ & $\mathrm{X}$ & $\mathrm{X}$ \\
\hline Services to clients & $\mathrm{X}$ & $\mathrm{X}$ & $\mathrm{X}$ & $\mathrm{X}$ & $\mathrm{X}$ & $\mathrm{X}$ \\
\hline Local advertising & & & $\mathrm{X}$ & $\mathrm{X}$ & $\mathrm{X}$ & \\
\hline Cost analysis & & & & $\mathrm{X}$ & & \\
\hline Follow-up study & & & & $\mathrm{X}$ & $\mathrm{X}$ & \\
\hline Data analysis and reports & $\mathrm{X}$ & & $\mathrm{X}$ & & $\mathrm{X}$ & $\mathrm{X}$ \\
\hline
\end{tabular}

In June-July 1996, field visits were made to each of the clinics for standardization of the protocol and procedures for client screening, counseling, management of side effects, disposal of waste material, data recording arid reporting and pilot testing the newspaper advertisements. Throughout the study, staff from the Population Council, USAID and PSS headquarters visited each of the sites to make direct observations and to see that standardized procedures were being followed. Given that PSS is a service rather than a research organization, the volume of data collected and scheduling of interventions was well managed. PSS also learned a great deal about the management of operations research and timely utilization of emerging information during the process. 


\section{Results}

\section{A. Number of Clients}

The study was designed to examine the effect of DMPA price at three PSS clinics on the number of clients using injectables and the number of doses provided over time. Table 4 describes the total number of clients and DMPA doses provided during the study. In absolute terms, price clearly made a difference in the total numbers of clients and DMPA injections given within the same period of time at the three clinics. In Varanasi, where DMPA was available at no charge, there were a total of 298 DMPA clients and 473 doses given; at Agra (Rs 50) there were 199 clients and a total of 324 doses administered; and at the highest price Rs 100 in Lucknow, there were 165 women served and a total of 297 doses administered between April 1996 and September 1997.

\begin{tabular}{||l|l|l|l|l||}
\hline \hline DMPA Dose & Total & Varanasi & Agra & Lucknow \\
\hline \hline First Dose (clients) & 662 & 298 & 199 & 165 \\
\hline Percent of Acceptors \% & & 45 & $\mathbf{3 0}$ & 25 \\
\hline
\end{tabular}

In terms of total doses provided, the volume of DMPA use in these clinics is relatively modest. Less than 1100 doses were provided during the I8 month study period. However, information from all thirty PSS clinics in the country indicate that a total of 2849 injections of DMPA were provided in the year July 1996 to June 1997. Of these, about 33 percent were provided in the three study clinics in Agra, Lucknow and Varanasi alone.

The data in Figure 1 show the number of first doses provided over time at each of the clinics. Note that not all the clinics began at the same level, e.g. the number of users in Agra had already increased to nearly 50 during April-June 1996 from a pre-project number of less than 15 . It is evident from the figure that following the price change, there was an increment in first time use in all three clinics. In Varanasi and Agra, the number of new acceptors decreased slowly thereafter, even during the period of advertising from October 1996 to March 1997. In Lucknow, at the highest price, first time users peaked during the semester when the advertising occurred and only thereafter declined. 
Figure 1. New DMPA Acceptors Over the Study Period

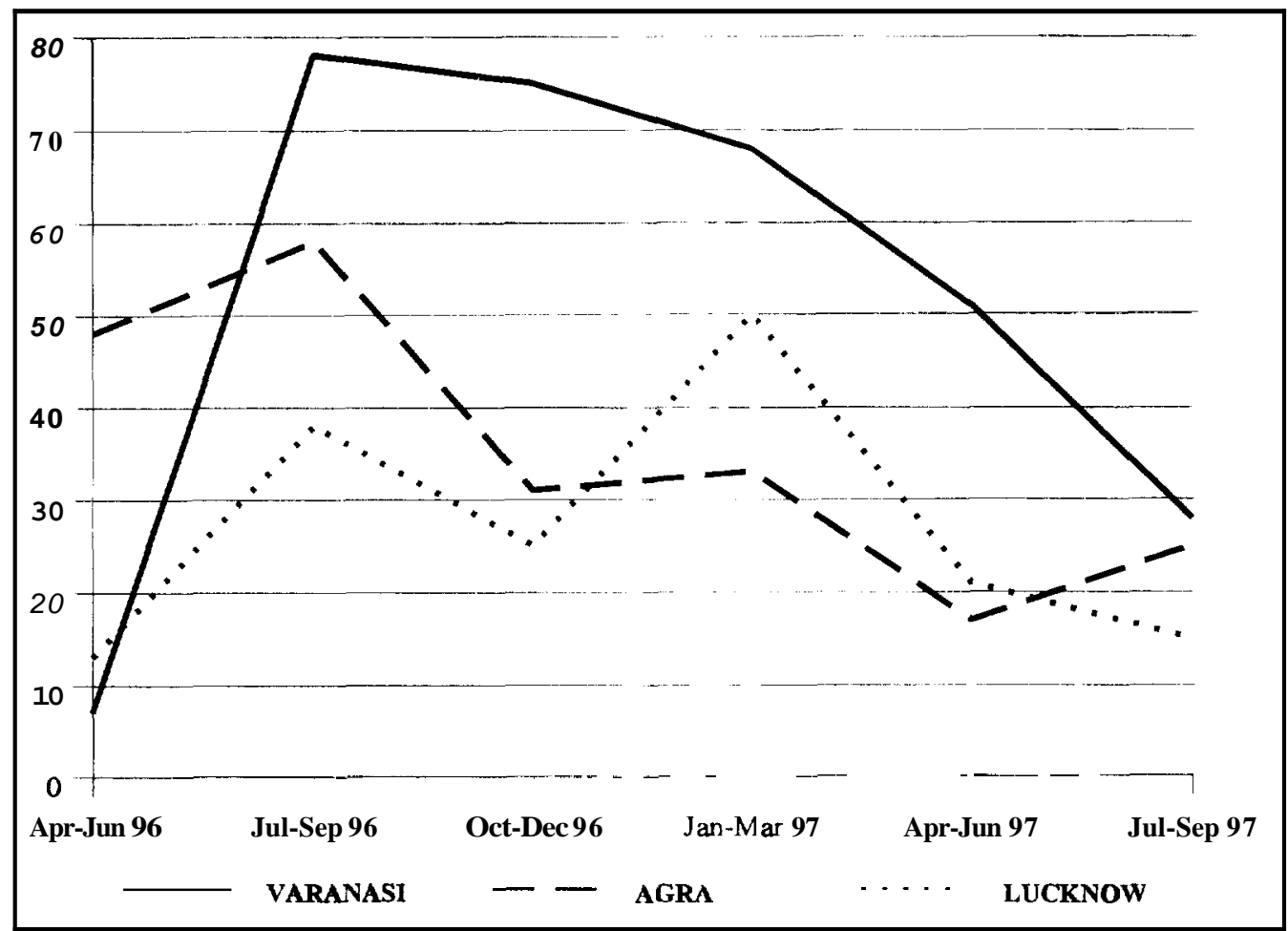

Table 5. DMPA Acceptors at the Three Clinics Apr 1996 to Sep 1997

\begin{tabular}{|c|c|c|c|c|c|}
\hline & & & $\begin{array}{l}\text { Varanasi } \\
(\mathrm{N}=298)\end{array}$ & $\begin{array}{l}\text { Agra } \\
(\mathrm{n}=199)\end{array}$ & $\begin{array}{l}\text { Lucknow } \\
(\mathrm{n}=165)\end{array}$ \\
\hline $\begin{array}{l}\text { Apr 96-Jun } 96 \\
3 \text { months }\end{array}$ & $\begin{array}{l}\text { DMPA at Rs. } 150 \\
\text { Trained providers }\end{array}$ & 70 & 8 & 48 & 14 \\
\hline \multicolumn{3}{|l|}{ July 1, 1996} & \multirow[t]{2}{*}{ Rs. $0+40$} & Rs. $50+40$ & Rs. 100 \\
\hline $\begin{array}{l}\text { Jul } 96-\operatorname{Sep} 96 \\
3 \text { months }\end{array}$ & No Advertisements & 170 & & 57 & 39 \\
\hline $\begin{array}{l}\text { Oct } 96-\text { Mar } 97 \\
6 \text { months }\end{array}$ & $\begin{array}{l}\text { Newspapers, magazines and } \\
\text { billboards used for advertising }\end{array}$ & 268 & 138 & 54 & 76 \\
\hline $\begin{array}{l}\text { Apr } 97-\text { Sep } 97 \\
6 \text { months }\end{array}$ & Print advertisements terminated & 154 & 78 & 40 & 36 \\
\hline Apr 96-Sep 97 & $\begin{array}{l}\text { Mean Acceptors of DMPA per } \\
\text { month }\end{array}$ & 37 & 17 & 11 & 9 \\
\hline
\end{tabular}


As can be seen from Table 5, with the exception of Agra, the largest increase in total users occurred during the period from October 96 to March 1996 when advertising was being conducted. While the monthly differences are not dramatic they are consistent with the hypothesized relationship to price. As advertising through the print media was discontinued in April 1997, the number of new acceptors diminished in all three sites.

\section{Relative Use of DMPA}

The distribution of family planning users by method at the three clinics is given in Table 6 below. At the three PSS sites, DMPA represented approximately 14 percent of all female contraceptive acceptors annually It also accounted for about 5-8 percent of the family planning clinic visits to PSS.

Table 6 Percentage of Family Planning Methods Provided Apr 1996 - Sep 1997

\begin{tabular}{|l|c|c|c|c|}
\hline $\begin{array}{l}\text { Contraceptive } \\
\text { Methods }\end{array}$ & Total $\%$ & Varanasi & Agra $\%$ & Lucknow \\
\hline \hline Tubectomy & 28 & 23 & 44 & 10 \\
\hline IUD (acceptors) & 20 & 19 & 23 & 19 \\
\hline OCPs (acceptors) & 38 & 41 & 23 & 60 \\
\hline DMPA (acceptors) & 14 & 17 & 10 & 11 \\
\hline Total Acceptors & 5314 & 1747 & 2073 & 1494 \\
\hline
\end{tabular}

Acceptors $t$ defined as the number of cycles of orals pro: idec divided by 13

The most popular method provided by PSS was pills, which were distributed through both the clinic and outreach services. Tubectomy was the second most common method, followed by the IUD. There were significant differences in terms of method use by site, with tubectomy the most common in Agra and orals the most common in Lucknow. When the study began, it appeared as if DMPA sales were partially replacing the sale of orals. However, as the study progressed, there was only a modest change in the overall method mix.

Figure 2 provides an illustration of the trends in method acceptance for all 30 PSS clinics nationally over the time period of the study. Since January 1995, there has been a notable seasonal pattern in the number of IUDs inserted (1500 to 2300 per quarter) and sterilizations conducted (from 3500 to 7000 per quarter). The greatest number of cases occurs in the first quarter of each year and in the fourth quarter. This is the winter in India. and a traditional time lor adopting clinical methods. In contrast, there has been a gradual increase in the number of DMPA acceptors through 
the first quarter of 1997, followed by a gradual reduction. At the same time that DMPA use slowed, there was a large absolute increase in the number of cycles of orals distributed nationally, an increase of almost 300 percent. For all PSS clinics, the number of DMPA acceptors represents about 14 percent of the total number of sterilizations, and 36 percent of the number of IUD acceptors during 1997.

\section{Figure 2. Method Mix at PSS Clinics Nationally}

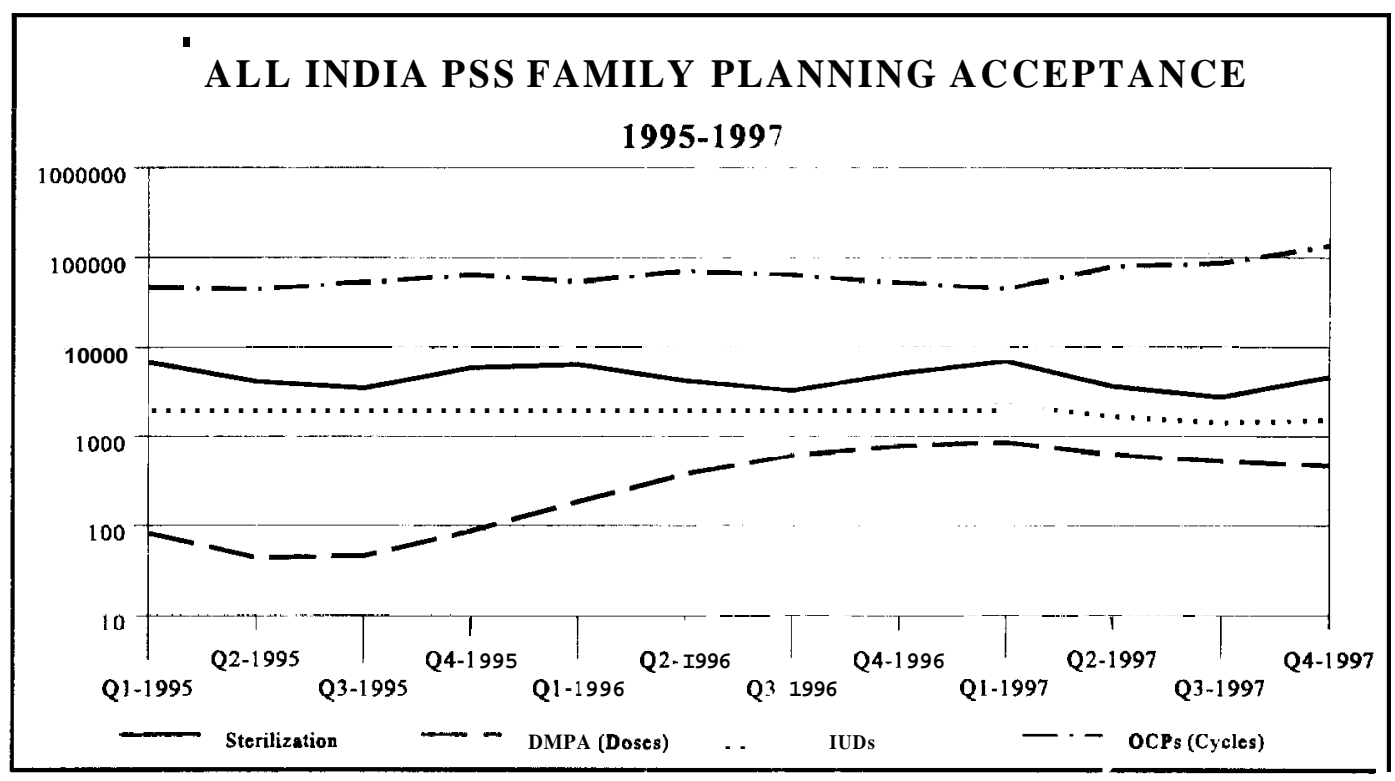

Data from shelf audits conducted by ORG during the study period illustrated little commercial sale of DMPA in the state. For example, data on the total number of vials sold by commercial outlets in Uttar Pradesh from April to September, 1997 show that only 600 vials were distributed, 100 were sold and 500 were still in stock at the outlets (ORG, 1997). Thus, commercial sales of DMPA in UP are still very low. The DMPA used for the present study was supplied directly by the PSS office in New Delhi and is not reflected in the shelf audits.

\section{B. Characteristics of Clients}

Table 7 provides information on the general characteristics of acceptors. Virtually all users stated that they were married. The median age of acceptors is about 27 years, although clients ranged in age from about $\mathbf{1 8}$ to about 40 years of age. In terms of religion, they reflected the profile of the communities in Uttar Pradesh in which they live. Most were Hindu, but about 13 percent were Muslim, Sikh, Christian or other. Given the urban nature of the clinics, women's education was 
quite high with about 85 percent having some education, and 42 percent more than 12 years of schooling. Their husband's had slightly higher levels of education.

Data from the client record suggests that nearly half come from homes with a monthly family income greater than Rs. 3000 (about US\$85). The women tended to be better educated, and have on average a smaller family size than the general population of Uttar Pradesh. Women selecting DMPA were relatively similar across the three clinics. Yet, DMPA users in Lucknow were somewhat more educated and affluent, and worked more outside the home than DMPA users in Agra or Varanasi.

Table 7 Characteristics of DMPA Users According to the Clinic Card

\begin{tabular}{|c|c|c|c|c|}
\hline VARIABLE & $\begin{array}{l}\text { All Clients } \\
\%\end{array}$ & $\begin{array}{c}\text { Varanasi } \\
\%\end{array}$ & $\begin{array}{c}\text { Agra } \\
\%\end{array}$ & $\begin{array}{c}\text { Lucknow } \\
\%\end{array}$ \\
\hline $\begin{array}{l}\text { Age - median years } \\
\quad<21 \\
21-25 \\
26-30 \\
31-35 \\
>35\end{array}$ & $\begin{array}{r}27 \\
9 \\
32 \\
34 \\
16 \\
8\end{array}$ & & & \\
\hline $\begin{array}{l}\text { Religion } \\
\text { Hindu } \\
\text { Muslim } \\
\text { Sikh/Christian/Other }\end{array}$ & $\begin{array}{r}87 \\
9 \\
4\end{array}$ & & & \\
\hline $\begin{array}{l}\text { Education } \\
\text { None } \\
1-12 \\
\text { Graduate } \\
\text { Vocational } \\
\text { Post-Graduate }\end{array}$ & $\begin{array}{r}16 \\
43 \\
22 \\
5 \\
15\end{array}$ & & & \\
\hline $\begin{array}{l}\text { Husband's Education } \\
\text { None } \\
1-12 \\
\text { Graduate } \\
\text { Vocational } \\
\text { Post-Graduate }\end{array}$ & $\begin{array}{r}6 \\
33 \\
31 \\
5 \\
25\end{array}$ & $\begin{array}{r}7 \\
29 \\
27 \\
7 \\
30\end{array}$ & $\begin{array}{r}5 \\
49 \\
28 \\
3 \\
14\end{array}$ & $\begin{array}{r}7 \\
19 \\
44 \\
4 \\
27\end{array}$ \\
\hline Working outside home & 17 & 15 & 11 & 27 \\
\hline $\begin{array}{l}\text { Family Income per Month (Rs.) } \\
\quad<1500 \\
\quad 1500-3000 \\
\quad>3000\end{array}$ & $\begin{array}{l}17 \\
35 \\
47\end{array}$ & $\begin{array}{l}23 \\
31 \\
46\end{array}$ & $\begin{array}{r}15 \\
46 \\
39\end{array}$ & $\begin{array}{r}8 \\
31 \\
60\end{array}$ \\
\hline Total N & 662 & 298 & 199 & I65 \\
\hline
\end{tabular}




\section{Reproductive and Contraceptive History}

Table 8 provides information on the clients' reproductive and family planning history. On average acceptors of DMPA had been married about 8 years and had about 2.5 children. Often the differences between clinics were considerable, e.g. an average of 1.9 live births among acceptors in I ucknow compared to 2.7 live births in Varanasi. It is noteworthy that 12 percent of users in Lucknow had not yet had children. On average, women had experienced their last child birth two years previously, with about 36 percent of users giving birth during the past twelve months. As a result, 44 percent of the women were breastfeeding at the time of first DMPA acceptance. This is important as DMPA contains only progesterone, does not interfere with lactation, and is preferred over combined oral pills for breastfeeding women. Progesterone only pills are not available in India. The use of DMPA among young, low parity women is an important feature of the service from a demographic as well as reproductive health perspective.

Data from the client cards indicates that almost all the clients (94 percent) were aware of some method of camily planning, particularly sterilization. Ninety-five percent of the clients were aware of the availability of family planning services as well as Medical Termination of Pregnancy (MTP) services at PSS clinics. The level of awareness was almost identical in all three clinics. Among spacing methods the highest level of awareness was of condoms ( 89 percent). 88 percent were aware of the pill and 86 percent were aware of the II D.

The majority of women accepting DMPA had used another method of contraception previously. including 3 percent with earlier experience with DMPA. For 5 percent of new acceptors DMPA was the first contraceptive method they ever used. About 64 percent had used condoms at some time. 3.3 percent the IUD and 24 percent the oral pill. Two percent of users in Lucknow had undergone unsuccessful tubectomies. About half of the women had discontinued the previous method for a variety of reasons, including method failure and fanily concerns. About one-fourth had terminated the method due to unacceptabli side effects. The differences between clinics were notable. For example, 85 nercont of women in Agra reported having used the condom compared to only 40 peree 1 II Varanasi and 23 percent of women in Lucknow stated having used some traditional method compared to only 1 percent in Agra.

Approximately 35 percent of the women said that they were using DMPA as a method for spacing births. while 65 percent stated that they did not want any more children but were not yet ready for sterilization. Of clients accepting DMPA as a spacing method, 13 percent wanted a gap of fiv: years before conceiving again. 
Table 8 Reproductive and Familv Planning History

\begin{tabular}{|c|c|c|c|c|}
\hline Variables $Y_{o}$ & Total $\%$ & Varanasi $\%$ & Agra $Y_{0}$ & Lucknow \% \\
\hline Age at Marriage - median & 19 & 18 & 19 & 20 \\
\hline Mean Number of Live Births & 2.5 & 2.7 & 2.6 & 1.9 \\
\hline \multicolumn{5}{|l|}{ No. Living Children } \\
\hline None & 4 & 1 & 2 & 12 \\
\hline 1 & 20 & 19 & 14 & 27 \\
\hline 2 & 37 & 35 & 38 & 38 \\
\hline 3 & 18 & 19 & 21 & 13 \\
\hline 4 & 13 & 14 & 16 & 8 \\
\hline 5 or more & 8 & 11 & 10 & 1 \\
\hline \multicolumn{5}{|l|}{ Last Child Birth } \\
\hline Up to 12 months & 36 & 37 & 36 & 37 \\
\hline $13-24$ months & 18 & 21 & 21 & 10 \\
\hline 25-36 months & 10 & 6 & 17 & 10 \\
\hline More than 36 months & 33 & 35 & 26 & 40 \\
\hline \multicolumn{5}{|l|}{ Previous FP Methods Used } \\
\hline Condom & 64 & 40 & 85 & 72 \\
\hline IUD & 33 & 35 & 24 & 40 \\
\hline Pill & 24 & 26 & 22 & 24 \\
\hline Injectable & 3 & 3 & 2 & 3 \\
\hline Tubectom y & I & 0 & 0 & 2 \\
\hline Traditional methods & 10 & 6 & 1 & 23 \\
\hline Currently breastfeeding & 44 & 45 & 42 & 31 \\
\hline
\end{tabular}

\section{Sources of Information about DMPA}

According to the client intake card, which was completed by the clinic counselor, about 20 percent of DMPA acceptors were previously aware of injectable contraception prior to visiting the PSS clinic. The most commonly mentioned source of awareness for DMPA was the doctor in the PSS clinics (37 percent), followed by the media (33 percent) and then the client's husband and friends (14 percent each), although many mentioned multiple sources. Awareness was much greater in Lucknow (33 percent) and Agra (25 percent) than in Varanasi ( 7 percent). As DMPA is a relatively new method in India, health providers are important sources of awareness and their advice is relied upon by clients since women do not know others who use DMPA.

Given the historical controversy surrounding injectables in India, it is noteworthy that there was no adverse reaction from public authorities, women's health groups 
or clients to advertising on DMPA which appeared in Sunday newspapers and women's magazines over several months. Given the low key flavor of the campaign, it was seen as informational rather than promotional, and contained factual information available in the IEC materials. Public health authorities and the media had been briefed prior to the planned campaign by the local clinics.

\section{Use of DMPA Post-MTP}

Marie Stopes clinics provide safe and legal Medical Termination of Pregnancy (MTP) services, in addition to family planning and other reproductive health services. Women may seek care at PSS either for an MTP or care following an unsafe abortion occurring in another setting. All women seeking either an MTP or postabortion care are counseled and are encouraged to accept a reliable form of contraception following the procedure. Acceptance of contraception is voluntary and not a requirement for receiving any service. DMPA is an acceptable post-MTP method as it provides adequate contraception within 8 hours of injection. Its use also allows women time to discuss and accept longer term contraception with their partners and families as desired.

\begin{tabular}{|l|c|c|c|c|}
\hline \multicolumn{7}{|l|}{} \\
\hline Apr 96 - Sep 96 & 75 & 62 & 87 & 74 \\
\hline Oct 96 - Mar 97 & 56 & 45 & 78 & 57 \\
\hline Apr 97- Sep 97 & 26 & 8 & 62 & 28 \\
\hline Total (7 missing cases) & 54 & 37 & 79 & 56 \\
\hline
\end{tabular}

Table 9 presents information on the proportion of first time users who accepted DMPA after an MTP at all three sites. During the study period, 10,805 MTPs were carried out in the three clinics. Of these clients, about 3 percent (323) accepted DMPA. Over the study period. 54 percent of first time users of DMPA had just received an MTP. The differences between clinics is remarkable with 37 percent of DMPA using accepting post-MTP in Varanasi compared to 79 percent in Agra. However, there was no part of the training or clinical guidelines in any site that strongly recommended or emphasized use of DMPA at this particular time. Discussions with providers suggest that given the high volume of MTP users at these clinics, the pool of potential acceptors among this group was high. In all clinics however, the percent of reporting DMPA acceptance post-MTP declined over the period, as users began requesting the method as a routine family planning method. 
Analysis of the characteristicsof post-MTP users indicates no statistically significant differences between acceptors post-MTP and other DMPA users.

\section{Experience with Side Effects}

The potential side effects of any method are a concern to providers and users alike, and are an essential area of discussion during counseling. The experience with sideeffects among acceptors in Uttar Pradesh was very similar to those found in previous studies involving DMPA. Of the 261 women who returned to the clinic for a first follow-up visit, about one-third reported no side effects. About another third (35 percent) of acceptors reported amenorrhoea, and 24 percent had irregular spotting and scanty menstrual discharge. Excessive menstrual discharge was reported by just 3 percent. DMPA acceptors were not asked to return to the clinic prior to their next scheduled injection, unless they had a particular concern or experienced side effects. One case of post-coital bleeding was identified as a suspected case of RTI. The pattern was similar for the second and subsequent visits, although the number of DMPA users who returned for a third and fourth check-up was only 53 and 20 respectively.

Table 10 Side-effects among Women who Returned for Follow-up Visit

\begin{tabular}{|l|c|c|}
\hline Side-effect & $\begin{array}{c}\text { at First Follow-up } \\
\mathrm{n}=261\end{array}$ & $\begin{array}{c}\text { \% at Second Visit } \\
\mathrm{n}=114\end{array}$ \\
\hline \hline No Side effects & 34 & 32 \\
\hline Amenorrhoea & 35 & $\mathbf{3 6}$ \\
\hline Scanty periods and spotting & 34 & 22 \\
\hline Excessive menstrual discharge & 3 & 7 \\
\hline Others, e.g. weight gain & 4 & 3 \\
\hline
\end{tabular}

The management of side effects was standardized through clinical guidelines in the three clinics. Following consultation with a physician, women with amenorrhoea or spotting were counseled and reassured about the nature of these side effects. A cycle of combined oral contraceptives was prescribed for women who reported menorrhagia, excessive menstrual discharge. Only 8 percent definitely stated that they were not willing to take the next DMPA injection because of' side effects. However, clinic data is not available on women who did not return for follow-up. Those returning may have done so either because of their interest in continuing DMPA use, or because they perceived the side effects severe enough to require a consultation. The qualitative data from the follow-up of users also provides data on perceptions of side effects and their influence on future use of DMPA. 


\section{Continuation}

The analysis included all women who took their first injection after July 1, 1996 when the price changed and it also took into account whether they could have had the next dose by September 30, 1997, the last day of the study. Table 11 provides the DMPA continuation rates at the three clinics. Of eligible clients (592), 44 percent continued with a second injection, 29 percent returned for the third injection, and 19 percent received a fourth injection (12 months). The three month continuation rates at all three clinics were of comparable magnitude, with users in Varanasi having the lowest rate of continuation (4 1 percent), followed by Agra (47 percent) and Lucknow with the highest rate at 48 percent.

Table 11 Life Table Analysis of Use of DMPA Jul 1996 to Sep 1997

\begin{tabular}{|l|l|l|l|l|l|}
\hline \hline \multirow{2}{*}{ Dose } & \multirow{2}{*}{$\begin{array}{l}\text { Number } \\
\text { Entering the } \\
\text { Interval }\end{array}$} & \multicolumn{4}{|l}{ Cumulative Proportion Continuing DMPA Use } \\
\cline { 3 - 7 } & Total & Varanasi & Agra & Lucknow \\
\hline \hline 2nd Dose & 592 & 0.44 & 0.41 & 0.47 & 0.48 \\
\hline 3rd Dose & 217 & 0.29 & 0.3 & 0.23 & 0.31 \\
\hline 4th Dose & 103 & 0.19 & 0.19 & 0.16 & 0.21 \\
\hline Median Months of Use & 5.7 & 55 & 5.8 & 5.9 \\
\hline
\end{tabular}

All three clinics report median use of less than 6 months. There was no difference in continuation between those who received the method following an MTP and others. Nor was an association found between continuation and other variables such as reproductive intentions (spacing versus limiting), breastfeeding status, income, or education. No discontinuation of the method was recorded due to the failure of the method. There was only one case in which a woman, who had discontinued DMPA due to amenorrhoea following the first injection, returned eight months later pregnant.

Continuation rates among clients improved significantly over the study period. More than half of the clients ( 55 percent) who received their first injection during the second half of the study returned for the second dose and 39 percent for the third dose. The median duration of use during the second half of the study was $\mathbf{6 . 3}$ months, compared to 5.3 during the first half of the study. This suggests that procedures for client selection and counseling improved with experience.

These continuation rates are lower than those commonly cited in the literature (Population Reports, 1987). For example. a multinational study conducted by WHO reported in 1982 that continuation rates for DMPA at $\mathbf{6}$ and 12 months were 68 
percent and 49 percent respectively. Studies in Bangladesh, where DMPA was introduced in the public sector in 1976, commonly report continuation rates of around 50 percent at 12 months (Phillips, et al 1990). The difference with the PSS experience may be a function of the lack of outreach for follow-up, the limitation of a single site for obtaining the service, or the characteristics of clients who use PSS clinics. All three factors have the potential for limiting continuation of a given product.

\section{Clients' Perception of DMPA Experience}

The perceptions of potential clients and actual users of DMPA were probed through two qualitative substudies conducted as a follow-up. First, nine focus group discussions were carried out in the three cities with a total of about 80 women, aged 21-45, who had never used DMPA. The study reported their perceptions about family planning methods in general. and their awareness and perception of DMPA. Second, in order to understand womens' perceptions of DMPA, another qualitative study conducted in-depth interviews with 176 c urrent and 114 lapsed users in all three cities. All subjects for follow-up were selected from the list of women consenting to be contacted at home from the PSS clinics.

\section{Awareness of DMPA among Non-Users}

For non-users of DMPA, the most important consideration in selecting a contraceptive method was "effective protection from unwanted pregnancy". The other considerations were freedom from side effects, ease of use, acceptance by husband and stories of positive experiences on DMPA from friends. relatives and. most importantly other users.

Oral pills, IUD, condoms and tubectoniy uere the most commonly known and used contraceptives across all three sites irrespective of age groups. Never users in all three cities were only vaguely aware of the availability of an injectable contraceptive in Uttar Pradesh. They lacked any informed avareness of the method; for example, when it could be used, how- frequently it had to be used, its potential advantages and disadvantages and the cost per injection. Many thought that it required an examination and clinical tests before use. However, when it was explained to them that DMPA was a three-monthly injection that works as a contraceptive, it was seen as a good alternative choice.

The sources of information on DMPA mentioned by never users were the newspaper and magazines, radio and doctors. Some mentioned the specific newspaper or magazine they had seen the advertiscment in. As none of the women had tried 
DMPA, they did not have any knowledge of side effects. Their comments included the following:

"Seenother ads but never seen this one... hence did not try"

"Neverseen or heard anybody using it.. The ads don'tshow any experienced lady talking..new product...injections after all.. was not sure"

When asked if they knew how much it cost, very few could mention the price. However, when asked how much they would be willing to pay for such a contraceptive, the price range of Rs. 50-100 every three months seemed reasonable provided it met with their expectations. Comments included:

"If it costs Rs. 50, it is quite reasonable Pills might he cheaper but then it has a lot of botheration also"

"If it is Rs 150 also I know it becomes costly hut I may still go for it to become tension free."

"Think about the cost of abortion...its pain... its bad effects on health ... its costs, consider the cost of bringing up a child today.. I think it is worth even a little extra".

The major reasons for not trying DMPA were a lack of informed awareness of the product and lack of reassurance from current users. For a new coctraceptive method in India, word of mouth may be the best advertisement. Recall of the DMPA ads was low even after exposure. The absence of live role models (i.e. friends, relatives who had used DMPA and were satisfied) failed to create credibility for DMPA.

\section{Experience of Current and Lapsed Users of DMPA}

A total of 176current users (CU) and 114 lapsed users (LU) were interviewed at their homes at least 6 months following their acceptance of the product. Analysis of the demographic and socio-economic profile of current and lapsed users showed that there were no significant differences between the two groups. Moreover, there were few differences between the continuing and lapsed users on awareness of the IUD, pills, condoms and other spacing methods

According to Table 12, respondents in the follow-up mentioned that the most important sources of information on DMPA were husbands, friends, relatives, clinic personnel and the family doctor. Word of mouth was the main source of information as advertising merely let people know it was available. Recall of advertisements or 
wall paintings was not high, especially among lapsed users. Exposure to the advertisements was not as salient as a live example. Respondents preferred to hear about DMPA from a satisfied user, rather than through advertisements. Only 35 percent of current users (CU) and 25 percent of lapsed users (LU) had actually seen the advertisements. Of those who had seen the advertisements, 63 percent of $\mathrm{CU}$ and 75 percent of LU had seen them in the print media. and 34 percent of current users and 21 percent of LU had seen the wall paintings.

\begin{tabular}{|l||c||c|}
\hline \hline Sources & Current Users\% & Lapsed Users\% \\
\hline \hline Husband & 27 & 37 \\
\hline Friends/neighbours & 24 & 26 \\
\hline Hospital/FP clinic & 26 & 27 \\
\hline Advertising & 15 & 10 \\
\hline Sister/sister-in-law & 9 & $\mathbf{1 4}$ \\
\hline Mother & 5 & 5 \\
\hline Family doctor & 3 & 2 \\
\hline Total & $\mathrm{n}=176$ & $\mathrm{n}=114$ \\
\hline
\end{tabular}

\section{Knowledge about DMPA}

The level of knowledge about DMPA among both current and lapsed users was high, with regard to instructions for use, side effects and indications (see Table 13).

\begin{tabular}{|l|c|c|}
\hline \hline \multicolumn{1}{|c|}{ Counseling and IEC Messages } & $\begin{array}{c}\text { Current User } \\
\mathrm{n}=176\end{array}$ & Lapsed User \\
\hline \hline DMPA injections are given once in every 3 months. & 99 & 98 \\
\hline DMPA injections should be given only by doctors/nurses. & 98 & 98 \\
\hline DMPA injections lead to side effects like irregular periods. & 76 & 92 \\
\hline It is quite easy to conceive after discontinuing DMPA injections. & 85 & 89 \\
\hline $\begin{array}{l}\text { The first DMPA injection has to be given within 5 days of } \\
\text { completion of last menstrual period. }\end{array}$ & 90 & 89 \\
\hline $\begin{array}{l}\text { The first DMPA injection can also be given immediately after } \\
\text { abortion. }\end{array}$ & 82 & 83 \\
\hline $\begin{array}{l}\text { DMPA injections provide better protection than other } \\
\text { contraceptives. }\end{array}$ & 74 & 65 \\
\hline DMPA injections do not protect against STD and AIDS & 48 & 44 \\
\hline
\end{tabular}

In general, this good level of knowledge is a reflection of the quality of the counseling provided by PSS, as alternative sources of correct knowledge about 
DMPA are limited in Uttar Pradesh. The IEC materials for clients as well as providers contained all these messages. The fact that DMPA does not protect against STD/AIDS was reported by less than half of the clients, suggesting that this issue was less frequently included in client communication.

\section{Perceived Advantages and Disadvantages of DMPA}

Women were asked about the perceived advantages and disadvantages of the method, regardless of their personal experience with the product. According to data in Table 14, protection against pregnancy was the single most important perceived advantage of DMPA, even among those who had stopped using it. Its longer duration of effectiveness makes it more attractive than methods which must be used daily, or in conjunction with sexual intercourse. One user reported that it meant "no tension for three months". In Lucknow, convenience and fewer side effects emerged as the perceived advantages. In terms of disadvantages, amenorrhoea, increase in weight and spotting were some of the significant disadvantages mentioned.

\begin{tabular}{|l||c|c|}
\hline \hline & \multicolumn{2}{|c|}{ Current Users \% } \\
& \multicolumn{2}{|c|}{ Lapsed Users \% } \\
\hline \hline Perceptions of DMPA & 57 & 74 \\
\hline \hline Effectiveness & 37 & 5 \\
\hline Easy to use & 15 & 13 \\
\hline Has no side effects & 5 & 26 \\
\hline Cost is not high & 2 & 4 \\
\hline Disadvantages & & \\
& & \\
\hline Menstrual cycle disruptions & 52 & 73 \\
\hline Weakness & 15 & $\mathbf{1 8}$ \\
\hline Bleeding & 5 & 11 \\
\hline Lack of interest in sex & 13 & 12 \\
\hline Pain in vagina/ abdomen & 24 & 14 \\
\hline Increase in weight/ swollen body & 11 & $\mathrm{n}=114$ \\
\hline Total & $\mathrm{n}=176$ & \\
\hline
\end{tabular}

\section{Reasons for Discontinuing DMPA}

Amenorrhoea and bleeding were the main reasons given by women for discontinuing use of DMPA, although about one-third mentioned multiple side effects. Other side effects mentioned were weakness, pain, vomiting and lack of interest in sex. Table 15 provides a distribution of which side effects were mentioned as reasons for 
discontinuing use. Other reasons for discontinuation cited included desire for another pregnancy ( 3 percent), and interest in a sterilization ( 5 percent).

The differences between clinics in side effects mentioned is noteworthy. For example, 20 percent of discontinuers in Agra mention bleeding, while bleeding or spotting are not mentioned by all in Lucknow and by only 6 percent of women who discontinued use in Varanasi. Recall that nearly 80 of DMPA acceptors in Agra had undergone an MTP, suggesting that some side effects may also be related to other clinical procedures the women had been exposed to. The importance of counseling cannot be over emphasized, particularly among women receiving multiple services.

Table 15 Side Effects Mentioned by Women who Discontinued DMPA Use

\begin{tabular}{||l|c|c|c|c|}
\hline \hline Side Effects & All\% & Lucknow \% & Agra \% & Varanasi \% \\
\hline \hline Multiple side effects & 30 & 26 & 25 & 39 \\
\hline Menstrual cycle stopped & 40 & 39 & 38 & 44 \\
\hline Weakness & 9 & 5 & 8 & 14 \\
\hline Bleeding/spotting & 9 & - & 20 & 6 \\
\hline Pain & 8 & 8 & 2 & 14 \\
\hline Vomiting & 4 & 3 & 7 & - \\
\hline Lack of interest in sex & 2 & - & - & 6 \\
\hline Total & $(114)$ & $(38)$ & $(40)$ & $(36)$ \\
\hline
\end{tabular}

\section{Method Used after Discontinuing DMPA}

Following discontinuation of DMPA, about 60 percent of women decided to use another family planning method (see Table 16). This suggests that many women continued to be concerned about an unwanted pregnancy and were unhappy with DMPA as a method choice. About one-fourth of discontinuers began to use condoms, and another 18 percent began taking orals. Recall that about 35 percent of all DMPA acceptors were interested in spacing rather than limiting births. Not all women returned to PSS for supplies as, for many, inexpensive supplies of orals and condoms were available through outlets closer to their home. In Varanasi, a large proportion of users (28 percent) adopted oral pills, and in Lucknow 16 percent adopted sterilization. In Agra and Varanasi a large number of acceptors who discontinued with the method (56 and 37 percent respectively) did not adopt any other method. 
Table 16 Family Planning Method Used After Discontinuing DMPA

\begin{tabular}{|l|c|c|c|c|}
\hline \hline Method Used & All\% & Lucknow\% & Agra \% & Varanasi \% \\
\hline \hline Condom & 26 & 39 & 27 & 11 \\
\hline Oral Pills & 18 & 13 & 15 & 28 \\
\hline Sterilization & 7 & 16 & - & 6 \\
\hline IUD & 7 & 13 & - & 8 \\
\hline Other & 1 & - & 2 & - \\
\hline None & 41 & 19 & 56 & 47 \\
\hline Total & $(114)$ & $(38)$ & $(40)$ & $(36)$ \\
\hline
\end{tabular}

\section{Intention to Use DMPA in the Future}

As seen in Table 17. when asked how long current users planned to continue with DMPA, respondents in Lucknow showed more interest to continue than those at clinics with lower prices. In Agra and Varanasi close to one-fourth of the women stated that they wanted to use DMPA for less than six months, while only 2 percent of women in Lucknow wanted to use it for such a short period. When data on the intention to purchase DMPA in the future was analyzed by experience with side effects, those with reported side effects showed a much lower purchase intent and less sensitivity to price increase than those who had experienced no side effects.

Table 17 Length of Intended use of DMPA among Current Users

\begin{tabular}{|l|c|c|c|c|}
\hline IntendedUse & Alा\% & Lucknow \% & Agra \% & Varanasi \% \\
\hline Up to 3 months & 15 & - & 8 & 34 \\
\hline 3-6 months & 18 & 2 & 23 & 28 \\
\hline 6-9 months & 5 & - & 7 & 8 \\
\hline $\begin{array}{l}\text { More than 9 months/ } \\
\text { regularly }\end{array}$ & 33 & $i 2$ & 45 & 5 \\
\hline Unsure & 29 & +6 & 17 & 25 \\
\hline
\end{tabular}

Figure 3 illustrates the impact on price on the future intention of current users to purchase DMPA, as measured by client's report they would "definitely" use DMPA at each price. The response of users differed significantly by clinic. For example, while fewer users in Lucknow and Agra indicated they would "definitely" use DMPA as the price varied from Rs. 50 to Rs. 150. in Varanasi only about 10 percent of current users planned to "definitely use DMP $A$ " at any price. Once a product is provided free. it appears that a substantial increase in cost would be unacceptable. Recall that there was little relationship of price to actual continuation among all acceptors. 
Figure 3 Price and Future Intent to Use DMPA

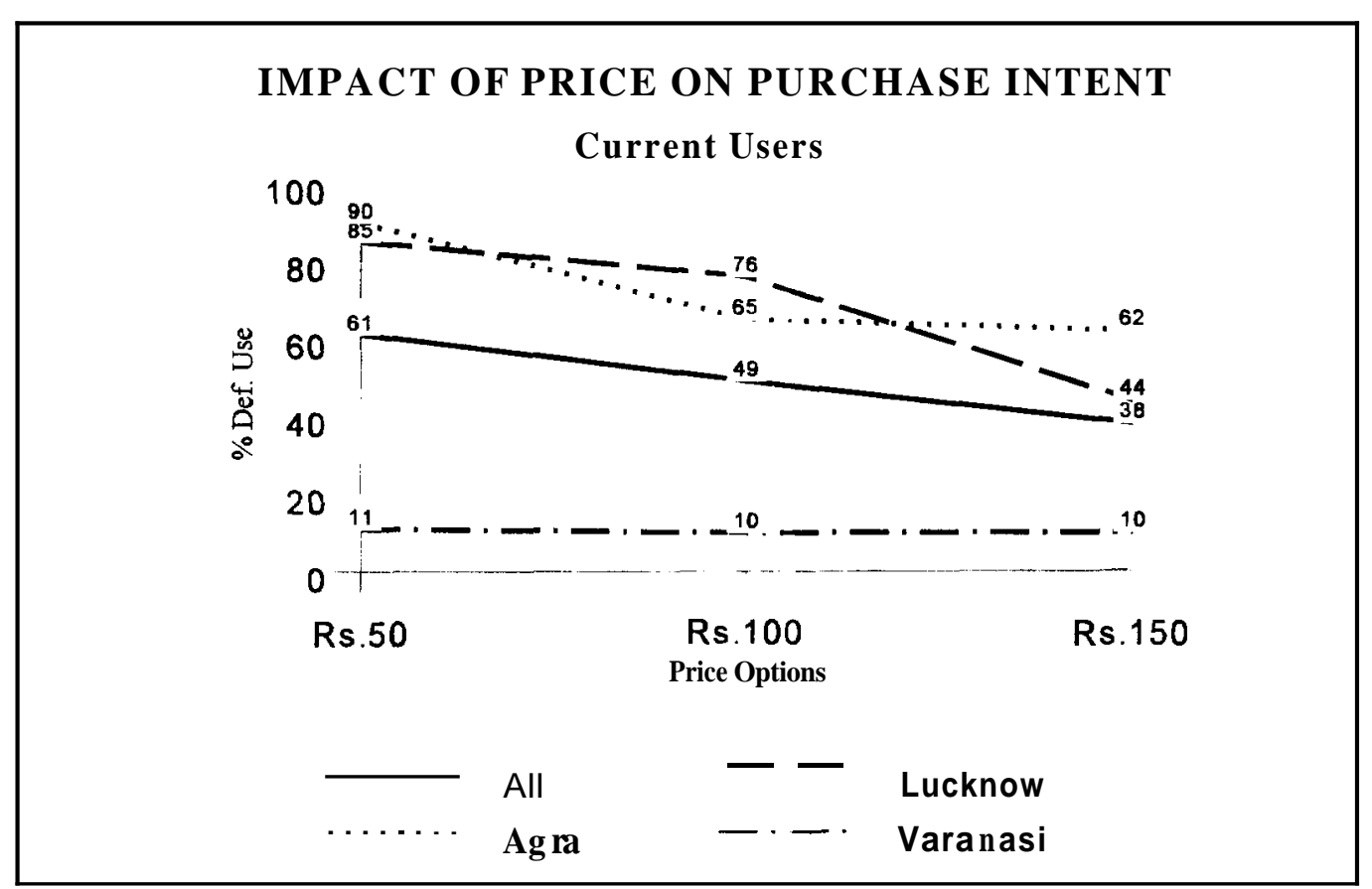

\section{Issues of Price and Marketing of DMPA}

There was a separate technical paper produced on the analysis of the cost of providing DMPA at all three PSS clinics (RamaRao et al, 1997). The analysis used a methodology which estimates cost based on major components of care, and the time spent in providing services to each individual client (AVSC, 1996; Janowitz and Bratt, 1994). 'The wholesale price to PSS of DMPA from Pharmacia \& Upjohn was about Rs. 95 per dose at the outset of the study. This price is variable as the wholesale price for the same product is currently about Rs. 120 in the Indian market. DMPA is available in the public sector at no cost to the client in Nepal and Bangladesh.

Table 18 presents a description of annual revenues and loss (or gain) based upon the annual costs of providing DMPA in each clinic. The cost per client was estimated based on the type of DMPA services provided. Prices varied by clinic due to the variation in the time spent by providers on each activity and the average number of clients served during a month. Total revenues from DMPA sales ranged from Rs. 13,080 in Varanasi to Rs. 29,160 in Lucknow. Despite the differences in the price charged for DMPA, the difference in revenue between Agra and Lucknow is not large, given the common fixed gynaecological fees charged at each site and the larger number of clients paying for services in Agra. 
Table 18 Annual Revenue and Loss/Gain

\begin{tabular}{|c|c|c|c|}
\hline Clinic & Revenue & $\begin{array}{l}\text { Loss/gain with } \\
\text { advertising }\end{array}$ & $\begin{array}{l}\text { Loss/gain without } \\
\text { any advertising }\end{array}$ \\
\hline $\begin{array}{l}\text { All Clients } \\
\text { Agra } \\
\text { Lucknow } \\
\text { Varanasi }\end{array}$ & $\begin{array}{c}25540 \\
29160 \\
13080\end{array}$ & $\begin{array}{l}-37049 \\
-21948 \\
-51515\end{array}$ & $\begin{array}{r}545 I \\
14081 \\
-7386\end{array}$ \\
\hline $\begin{array}{l}\text { Per Client } \\
\text { Agra } \\
\text { Lucknow } \\
\text { Varanasi }\end{array}$ & $\begin{array}{l}54 \\
68 \\
25\end{array}$ & $\begin{array}{l}-78 \\
-51 \\
-99\end{array}$ & $\begin{array}{r}12 \\
33 \\
-14\end{array}$ \\
\hline
\end{tabular}

Note: Minimum estimates of total costs used

Based on the annual costs and the income generated by the price of DMPA and clinical examination, an estimate of annual loss or gain from DMPA service provision was calculated for PSS. Estimates of advertising costs ranged frem about Rs. 72,000 in Varanasi to a maximum of Rs 108,000 in Agra (US\$2,016 to US $\$ 3,025$ ). It is clear that the costs of advertising can not be covered within the present pricing structure, even at the highest price of Rs. 100 per injection. However, if the advertising budget came from other sources, then Rs. 100 was the price at which clinics would be able to offer this service without a loss. However, this figure is heavily dependent on the wholesale price of DMPA. Clearly the procurement cost is the most important factor when assessing the cost feasibility of providing DMPA to women in the urban, lower, and middle income bracket.

Table 19 provides data on the comparative costs of products in the Lucknow market when the cost study was conducted in January 1907. Prices in the other cities varied little for these items. It should be noted that the median family income per month of acceptors interviewed in the follow-up was about Rs. 5000 (US\$140). At the price of Rs. 100 in Lucknow, DMPA is still relaticely expensive when compared with other products, such as cooking items, personal hygiene products, or clothing. It is even expensive compared to other contraceptives available through PSS. For example, orals such as Mala $\mathrm{N}$ and condoms such as Nirodh, government products which are distributed by PSS, are provided free of charge. Sterilization services are also provided free, and the government sanctioned user fee of Rs. 145 is paid to clients to cover their expenses. Many women who do not work outside the home may also have to ask their spouses for funds to cover the transportation costs, examination charge and DMPA purchase price.

But the purchase price is not the only consideration. For example, sanitary pads are still seen as a luxury for many urban women in Uttar Pradesh. If bleeding problems 
associated with DMPA use require additional sanitary protection, the effective cost of DMPA for the client would also increase. Likewise if the injections are only available at the PSS clinic, as opposed to the local pharmacist or medical practitioner, then the client's transportation costs and other opportunity costs to the client should also be considered.

Table 19 Comparative Prices in Lucknow Jan. 1996

\begin{tabular}{|l|l|}
\hline \hline ITEMS & PRICE Rs. \\
\hline \hline DMPA & 100 \\
\hline Orals (cycle of Ecroz) & 6 \\
\hline Condoms (3 pieces) & 5 \\
\hline MTP & $375-625$ \\
\hline Sanitary Pads (I 0) & 32 \\
\hline Pregnancy Test & 40 \\
\hline Tooth Paste (Tube) & 25 \\
\hline Sugar (1 kg) & 14 \\
\hline Cooking Oil (1kg) & 40 \\
\hline Eyebrow Threading & 12 \\
\hline Cigarettes (pack of 20) & 25 \\
\hline Saree (Cotton) & $150-200$ \\
\hline
\end{tabular}

Figure 4 illustrates the effect on net revenue to PSS when variations in the wholesale commodity prices of DMPA are assumed. At the wholesale price of Rs. 95, only Lucknow which charges Rs. 100 has a positive balance per 100 clients (Rs. 761). Were wholesale prices to be reduced to Rs. 65, L ucknow would still have a positive balance, but Agra and Varanasi would still require a subsidy. If the wholesale price were Rs. 35, then both Agra and Lucknow clinics would generate income from the sale of DMPA. Clearly, unless PSS receives DMPA through a donation, free distribution of the product would not be cost-effective. At the wholesale price of Rs. 35, Lucknow would generate over Rs. 12,000 for every 100 DMPA clients. While this would not be enough for advertisement through billboards, it might be sufficient to cover the cost of more interpersonal communication strategies, e.g. having clients interested in DMPA meet satisfied users. This analysis strongly suggests that PSS work closely with potential suppliers to reduce the cost of the commodity before expanding the availability of the product further. 
Figure 4. Net Income at Different Wholesale Costs and Consumer Prices

Net income at different wholesale costs and consumer prices

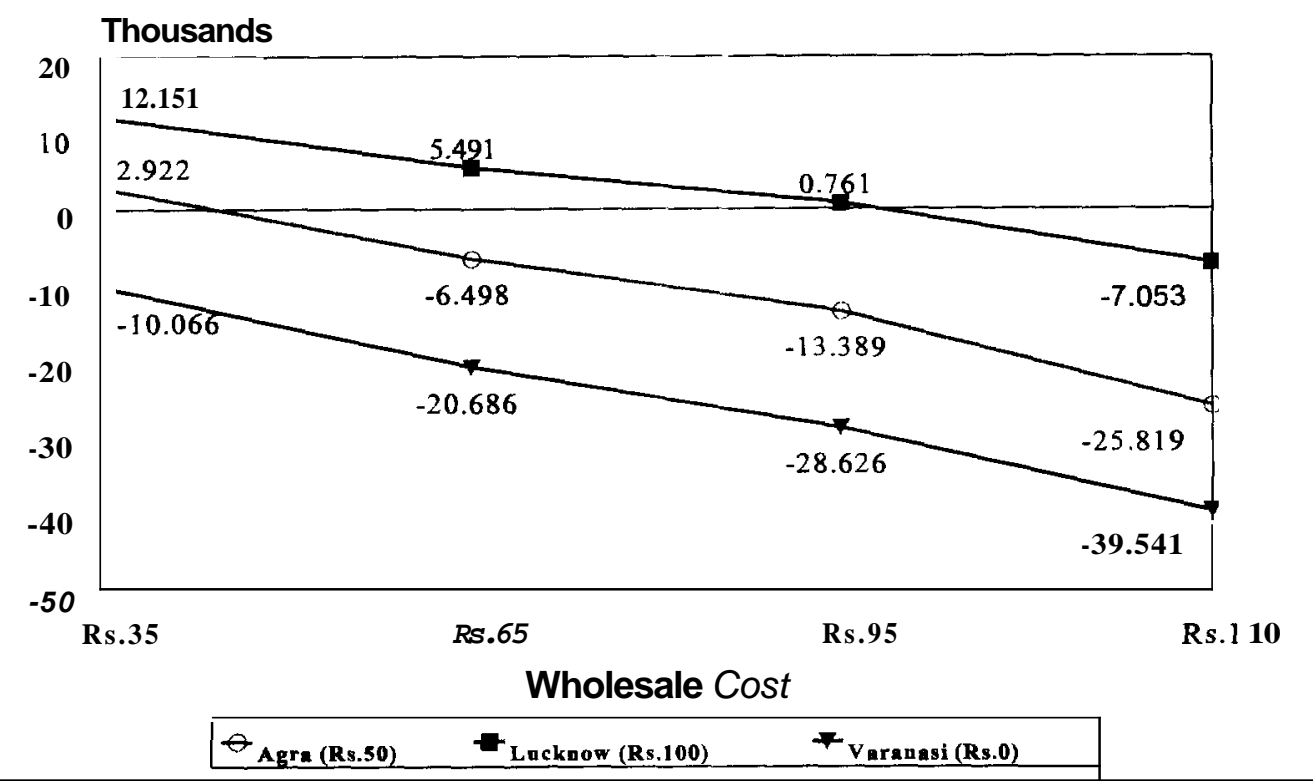

\section{Replicability}

There is still a great deal to be learned about the potential market for DMPA in India. Neither the manufacturer nor PSS is suggesting that the product should replace other contraceptive products alrezdy in the market. Rather the service is intended to expanded choices available to women, and as such it represents an important improvement to overall quality of care.

Counseling is an important element of quality in this study. In every clinic PSS employs an office manager, who is also responsible for client intake and provides counseling to clients before they see a physician. When replicating these services, it is critical that counseling be given priority to ensure that clients have adequate knowledge and understanding of IDPA and the likelihood of menstrual irregularities.

Many factors other than price affect access to this product, including client preferences, provider experience and the density of service delivery points offering the service. For example, one barrier to access to DMPA in the three cities studied 
is that PSS is the only major provider of the product. Other clinic sites where DMPA might be provided, e.g. KGM Hospital and the Family Planning Association of India clinic in Lucknow, report only a few users and no stocks on hand. Most women who want to use DMPA must go to the PSS clinic. rather than their local doctor or pharmacist. to obtain the service.

An important issue to remember is that PSS is already providing DMPA services in all its thirty clinics. PSS has been providing IDMPA in its clinics since 1994. As of October 1997. all clinics are providing the product at Rs. 50, the price charged at the Agra site. This is a major change since prior to the study all clinics were charging Rs. 150 for the same product. The cost study identified that at this price, while the services would have to be subsidized, the actual c ost to PSS of providing this service would be relatively modest given the number of clients. The critical issue for PSS to expand the service at this price, however. would be to ensure the supply of the commodity at a cost of around Rs. 35 .

Not to be overlooked is that fact that the needs of an important segment of clients, i.e. younger and lower parity women interested in spacing, are being met by this service. Moreover, they are willing to pay for the entire costs of the product and the service, as evidenced in the PSS clinic in lucknow. Several questions remain, however. What would the acceptability of the product be to clients of another source? Given the large number of MTP clients served by PSS, would another provider offer an alternative for a larger number of clients? What is the role of Pharmacia \& Upjohn in providing national marketing support to the product? And finally, what is the interest of the public sector in DMPA as part of its commitment to expanding contraception choices for couples

\section{CONCLUSION}

The results document that the DMPA services and counseling provided by PSS were of good quality. Initial use of the product seems to be sensitive to price in the context of Uttar Pradesh, while continuation is determined by a combination of factors, of which personal experience with the product is most important. In PSS's experience the role of the physician supplements that of the counselor for new clients. Continuing clients with amenorrhoea, however, want to be reassured that they are indeed not pregnant, and value contact with a physician.

The low key advertising of the services seemed to have little immediate effect on DMPA use, but at the same time there was no adverse response to the publicity. At the PSS clinics, about half of the users adopt DMPA following an MTP. The total number of clients served and doses provided is relatively modest in absolute terms, but significant relative to overall sales of the product in Uttar Pradesh, and segment of young, low parity PSS clients served. The c sts of providing the service for PSS 
appear affordable at the moment, with the cost of commodities being the most critical element to be resolved prior to further investment in expansion.

In conclusion, DMPA appears to be an acceptable, safe method of contraception when offered in a context of good client counseling and follow-up. By providing DMPA, PSS offered a broader contraceptive choice to their clients. More effective public information about the method and its availability would greater improve its access. Ensuring the availability of the product at an affordable wholesale price in India would both meet the needs of potential clients as well as facilitate the financial sustainability of the service by PSS. 


\section{REFERENCES}

AVSC International. 1996. Cost-Analysis Methodology for Clinic-Based Family Planning Methods. New York: AVSC International.

BSUP (Baseline Surveys in Uttar Pradesh). 1994. The Population Council and SIFPSA, Lucknow, Uttar Pradesh.

Ciszewski, R. L. and P.D. Harvey. 1995. "Contraceptive Price Changes: the Impact on Sales in Bangladesh". International Familv Planning Perspectives, Vol 21, Number 4, December.

CORT. 1995. Preliminary evaluation report on the effect of training IMA physicians on family planning in Uttar Pradesh, Baroda, Gujarat.

Costello, M. et al. 1995. Preliminary findings from the DMPA Monitoring Study, ANE OR/TA Project, Report to USAID. December.

Foreit, J.R. 1995. "Introduction of Depo-Provera in the CEMOPLAF Progam, INOPAL Summary Report, Quito, Ecuador.

ICMR. 1990. A multi-centre phase III comparative study of two hormonal contraceptive preparations NET-OEN (50 mgs) plus E2 valerate $(5 \mathrm{mg})$ given every month and NET-OEN (200 mgs) given every 2 months as intramuscular injection a report of a 12 month study. Contraception, Aug 42 (2): 179-190.

IIPS. 1993. National Family Health Survey (NFHS). 1993. International Institute for Population Studies and Macro International, Bombay.

Janowitz and Bratt. 1994. Methods for Costing Family Planning Services. New York: UNFPA and FHI.

Lewis, M.A. 1986. "Do contraceptive prices affect demand", Studies in Family Planning, 17:126-135.

Lewis, M.A. 1992. "Costs and cost sharing in family planning: a review of the evidence and implications for the future". Paper presented at the UN Expert Group Meeting on Family Planning, Health and Family Well-Being, Bangalore, India, Oct. 26-30, pp16-17.

ORG. 1997. Retail Shelf Audit of DMPA and other contraceptives in Uttar Pradesh, Operation Research Group, Baroda. 
Phillips, J.F., M.B. Hussain, A.A.Z. Huque and J. Akbar. 1990. "A case study of contraceptive introduction: domiciliary depot-medroxy progesterone acetate services in rural Bangladesh." In Demographic and Programmatic Conseuuences of Contracentive Innovations. (Eds. S.J. Segal. A.O > Tsui and S.M. Rogers), Plenum Press, New York and London, pp 227-248.

Pile, John. 1997. Personal Communication.

Population Reports. 1987. "Injectables and implants." Series K, Number 3, MarchApril.

Purandare, Mandakini. 1997. Evaluation of DKT India's Initial Experience with Injectable Contraceptives Net-in (Noristerat). Final report, DKT India, Mumbai.

RamaRao, Saumya., J.W. Townsend. Leila Caleb, Sudha Tiwari, Sneh Vishwanath and Harbans Singh. 1997. DMPA Provision in Parivar Seva Sanstha Clinics in Uttar Pradesh: Costs and Prices, Technical Paper 10, The Population Council: New Delhi, September.

Singh, Meena. 1995. "A report on the DMPA Experience at Parivar Seva Sanstha", Paper presented at the FOCSI meeting in New Delhi, Kanpur, UP, December.

UNFPA. 1993. Report: Contraceptive requirements and logistics management needs in India. New York.

WHO. 1994. Demographic Data Sheet, World Health Organization, Geneva. 